\title{
Polyvalent heat-killed antigen for the diagnosis of infection with Legionella pneumophila
}

\author{
RJ FALLON, WH ABRAHAM \\ From the Department of Laboratory Medicine, Ruchill Hospital, Glasgow G20 9NB
}

SUMMARY A polyvalent antigen composed of heat-killed agar-grown Legionella pneumophila serogroups 1-4 suspended in a suspension of yolk-sac from embryonated hens' eggs has been examined for use in the indirect fluorescent antibody test for Legionella infection. The serological response detected by monovalent antigen correlated well with that detected by polyvalent antigen. The use of polyvalent antigen forms a useful screening test for the detection of antibody to L pneumophila, but positive results must be confirmed by tests using monovalent antigen.

When it is was recognised that there was more than one serogroup of Legionella pneumophila ${ }^{2}$ it became obvious that the work of screening sera for antibodies to legionellas using the indirect fluorescent antibody test (IFAT) could be multiplied by the number of serogroups discovered because patients might produce antibody which was detectable only by antigen made from a particular serogroup. It was soon shown ${ }^{3}$ that patients infected with $L$ pneumophila could produce an antibody response to more than one serogroup of $L$ pneumophila. Nevertheless, this did not preclude the possibility of a response to a single serogroup antigen, particularly early in the infection. We, therefore, investigated the possibility of using a polyvalent antigen made using heat-killed organisms suspended in a suspension of yolk sac. $^{3}$ Preliminary results ${ }^{4}$ with an antigen composed of organisms of serogroups 1-4 were encouraging and we here report our experience with this antigen during 22 months of use in the routine diagnosis of $L$ pneumophila infection, together with comment on further polyvalent antigens composed of serogroups 5 and 6 and other Legionella spp.

Material and methods

\section{ANTIGEN}

Serogroups 1-6 of Legionella pneumophila were received from the Centers for Disease Control, Atlanta, as cultures on agar slopes. The organisms were propagated on charcoal yeast-extract (CYE) agar, 56 care being taken to work with only one serogroup at a time and to incubate cultures of each serogroup in separate containers (in an atmosphere of $5-10 \% \mathrm{CO}_{2}$ ) to avoid cross-contamination. The strains are shown in Table 1 . Cultures were grown at $36^{\circ} \mathrm{C}$ for $72 \mathrm{~h}$ on CYE agar plates and were then harvested in phosphate-buffered saline

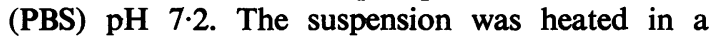
boiling water bath for $15 \mathrm{~min}$, centrifuged and the deposit suspended in distilled water. Sodium azide was added to a final concentration of $1 \%$. For use organisms were suspended in an $0.5 \%$ suspension of normal yolk sac from 8-10 day-old fertile hens' eggs in PBS pH 7.2. The density of each suspension was such that a Gram-stained film of a one in four dilution (in the case of serogroups 1-4) or one in two (serogroups 5 and 6) showed discrete organisms at a magnification of $\times 1000$. Hence, the final dilution would, if made in PBS (as opposed to $0.5 \%$ yolk sac) have had a density of approximately 5 International Opacity Units. Suspensions were stored at $4^{\circ} \mathrm{C}$.

PREPARATION OF ANTISERA

Rabbit antisera were prepared against $L$ pneumophila serogroups $1-6$ by inoculating rabbits with organisms

Table 1 Strains of $L$ pneumophila used for antigen production

\begin{tabular}{ll}
\hline Serogroup & Strain \\
\hline 1 & Philadelphia-1 \\
2 & Togus \\
3 & Bloomington-2 \\
4 & Los Angeles-1 \\
5 & Dallas i-E \\
6 & Chicago-2 \\
\hline
\end{tabular}


harvested, either from enriched Mueller Hinton agar $^{7}$ (for serogroups 1 and 2) or CYE agar plates for the remaining serogroups, into $1 \%$ formalin in PBS pH 7.2 and held at $37^{\circ} \mathrm{C}$ overnight. The suspension was then diluted with PBS to $0.25 \%$ formalin and was further diluted in $0.25 \%$ formalin in PBS to the appropriate opacity reading. Intravenous injections were given three times weekly. The first two injections were of $0.5 \mathrm{ml}$, thereafter $1 \mathrm{ml}$ was injected each time. For the first week, the opacity of the suspension was 20 units, second week 40 units and third week 160 units. Injections were continued three times a week with $1 \mathrm{ml}$ of the latter suspension until the serum titre in the IFAT was at least 8000 . These sera were used to establish the purity of the individual antigens before incorporation in the polyvalent antigen, as well as to test the reaction of individual antigens in the polyvalent antigen.

\section{HUMAN SERA}

These were received in the diagnostic routine service of the laboratory and also, for tests of the performance of the antigen, from Drs AD Macrae, AG Taylor and JO'H Tobin. Sera were used at doubling dilutions from 32 to 1024, rabbit sera at a range of dilutions which included an end point.

\section{INDIRECT FLUORESCENT ANTIBODY TEST}

This was performed using the technique described by Wilkinson et $a^{3}$ using fluorescein isothiocyanate (FITC)-conjugated antihuman globulin at a dilution determined by a chessboard titration with known positive serum. For tests with rabbit sera the FITCconjugate was swine antirabbit IgG supplied by Nordic Laboratories.

Antigens were spotted on to the wells of Tefloncoated slides (Hendley-Essex) bearing twelve 6 $\mathrm{mm}$ diameter wells. When dried the slides were fixed for $15 \mathrm{~min}$ in acetone. Sera were left in contact with antigen for $30 \mathrm{~min}$ at $36^{\circ} \mathrm{C}$, the slides were washed in PBS pH 7.2, then FITC-conjugated antispecies globulin was added to each well and the slides incubated for $30 \mathrm{~min}$ at $36^{\circ} \mathrm{C}$. Slides were then washed in PBS pH 7.2, dried and mounted in buffered glycerol pH 8 or latterly in polyvinyl alcohol mountant. 8

They were examined using a $\times 6$ eyepiece and $\times 40$ objective in a Leitz Dialux microscope with a Ploempak incident light fluorescent attachment incorporating a 50 watt mercury vapour lamp with a KP500 exciter filter, a K515 barrier filter and a TK510 dichroic mirror. The endpoint of the test was then fluorescing organisms were no longer visible. In each day's test, controls consisting of known negative and known positive serum were used. The titre of the original known positive serum had previously been established both in this laboratory and by Dr HW Wilkinson at CDC Atlanta. Tests using heat-killed antigen prepared at CDC and formalin-killed yolk sac antigen (FYSA) prepared from fertile hens' eggs inoculated with $L$ pneumophila and supplied by the Division of Microbiological Reagents and Quality Control (DMRQC), Central Public Health Laboratory, Colindale, ${ }^{9}$ were carried out in accordance with the instructions issued by the supplier. ${ }^{10}$

\section{E coli blocking fluid ${ }^{11}$}

This was made using a randomly selected strain of $E$ coli.

\section{Results}

INITIAL TESTS WITH KNOWN POSITIVE AND NEGATIVE SERA

Thirty-five sera (from 25 patients) all of which had been tested with serogroup 1 antigen in this laboratory previously and many of which had also been examined at CDC Atlanta ${ }^{12}$ were examined. Paired sera were examined from eight of the 25 adults and the serum pairs from two showed a greater than fourfold rising titre. Three serum specimens were obtained from a further adult and showed a fourfold rise and fall in titre. The changes in titre were demonstrated in these cases with both polyvalent and monovalent antigens. All but two of the sera had a titre of $>64$.

In addition, sera from 60 children, who would be unlikely to have antibodies to $L$ pneumophila, were examined as negative controls. All the children's sera were negative when examined at a dilution of 32. The results with adult sera are shown in Fig. 1. With polyvalent antigen, all the sera with one exception gave either the same titre as, or a titre one doubling dilution higher than, the titre with monovalent antigen. The tendency to give higher titres with polyvalent antigen was not surprising as, on testing with monovalent antigens prepared from serogroups 2,3 and 4, six of the eight sera so tested showed a substantial titre to one or more of these serogroups and hence there may have been an enhancement of fluorescence with the polyvalent antigen. However, this is not the whole explanation as several sera showing the same titre with both polyvalent and monovalent serogroup 1 antigens also reacted with antigens of serogroups other than 1.

TESTS WITH SERA FROM OTHER

LABORATORIES

The results of tests with 19 sera sent from other laboratories providing a service for the diagnosis of 


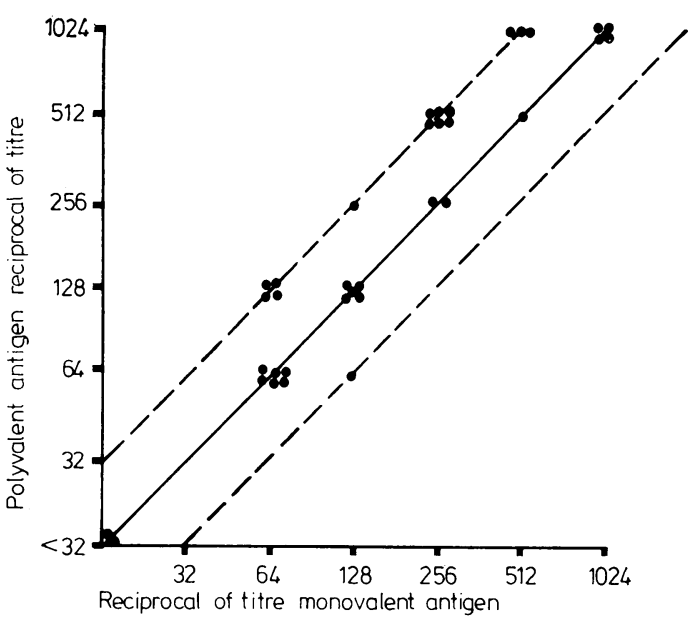

Fig. 1 Serum titre in the IFAT using polyvalent antigen compared with titres using monovalent serogroup I L pneumophila antigen. Thirty-five sera from 25 patients were examined.

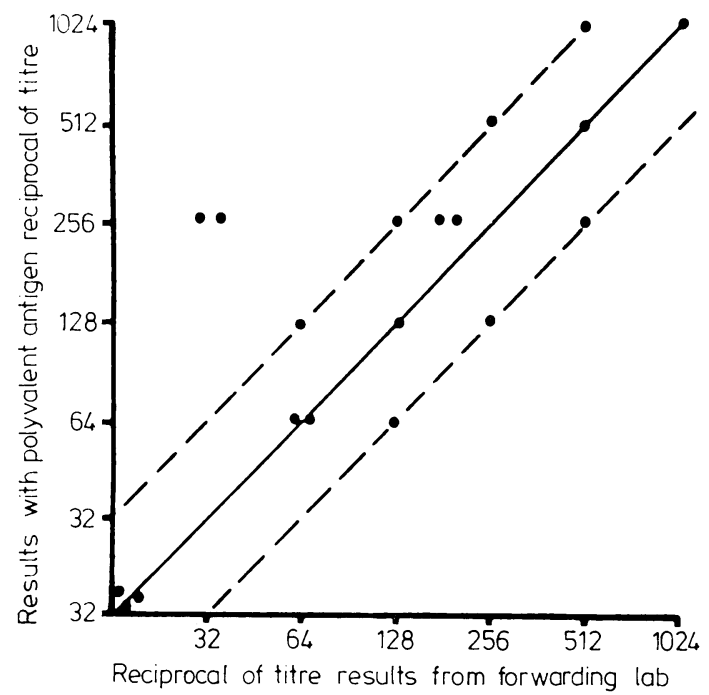

Fig. 2 Serum titres in the IFAT using polyvalent antigen compared with titres obtained by forwarding laboratories using monovalent L pneumophila antigen.

$L$ pneumophila infection, together with the results obtained in the forwarding laboratory, are shown in Fig. 2. The forwarding laboratories used monovalent antigen. The results show a close agreement between laboratories within the range of \pm one doubling dilution with the exception of two sera. These had been tested with FYSA and gave titres of 32 as compared with 256 using polyvalent antigen. One of these sera only gave a titre of 32 with monovalent heat-killed antigen. The other was shown, on testing with monovalent antigens, to react with serogroup 4 at a dilution of 128 and serogroup 2 at a dilution of 64 .

RESULTS OF ALL SERA

During the 22 months 1996 sera, from 1290 patients, were examined for the presence of antibodies to $L$ pneumophila using polyvalent antigen, positive results-that is, $>$ fourfold rising titres or titres $>256$, being confirmed with monovalent antigens. The results are shown in Table 2 . Of all sera $7 \cdot 1 \%$ examined gave titres of 64 or 128 but, when sera from patients with clinical Legionnaires' disease with positive serology, as defined above, are excluded, the figure becomes $5 \cdot 5 \%$. The 103 sera with a titre of $>256$ came from 51 patients, all of whom, with one exception, had a clinical illness compatible with Legionella infection. The exception was a patient with bronchial carcinoma whose two serum specimens gave a titre of 256 with both polyvalent and monovalent serogroup 1 antigen, indicative of infection at some time. The serological response in 67 cases of Legionnaires' disease was examined and the results are shown in Table 3. Thirty-six patients showed a response to one serogroup only and four of these were to serogroups other than 1 . In a further two patients there was no antibody response to serogroup 1.

Table 2 Examination of sera for antibodies to Legionella pneumophila using polyvalent antigens made from $L$ pneumophila serogroups $1-4$

\begin{tabular}{|c|c|c|c|c|c|c|}
\hline & \multicolumn{6}{|c|}{ Antibody titre observed } \\
\hline & $<32$ & 32 & 64 & 128 & $>256$ & Total \\
\hline $\begin{array}{l}\text { Number of sera } \\
\% \text { of total }\end{array}$ & $\begin{array}{l}1605 \\
80 \cdot 4\end{array}$ & $\begin{array}{l}146 \\
7 \cdot 3\end{array}$ & $\begin{array}{l}78 \\
3 \cdot 9\end{array}$ & $\begin{array}{c}64 \\
3 \cdot 2\end{array}$ & $\begin{array}{l}103 \\
5 \cdot 2\end{array}$ & 1996 \\
\hline $\begin{array}{l}\text { Number of sera } \\
\text { excluding those } \\
\text { from known cases }\end{array}$ & 1573 & 136 & 63 & 36 & 0 & 1808 \\
\hline$\%$ of total & 87 & $7 \cdot 5$ & $3 \cdot 5$ & 2 & & \\
\hline
\end{tabular}

Table 3 Serological response in 67 cases of Legionnaire's disease

\begin{tabular}{|c|c|c|}
\hline \multicolumn{2}{|c|}{ Monospecific serogroup I } & 32 \\
\hline & 2 & 1 \\
\hline & 3 & 1 \\
\hline & 4 & 1 \\
\hline & 6 & 1 \\
\hline \multirow[t]{3}{*}{ Reactions } & with two serogroups & 16 \\
\hline & with three serogroups & 9 \\
\hline & with four or more & 6 \\
\hline Total & & 67 \\
\hline
\end{tabular}

\section{Discussion}

The results show that polyvalent antigen detects anti- 
bodies to $L$ pneumophila and that the titres correlate well with those obtained with monovalent antigens. The results in Table 2 show that there is only a low level of background antibody detected using heatkilled polyvalent antigen, $5.5 \%$ of sera reacting at a level of 64 or 128 when sera from known cases are excluded. This antibody is not to be found in children. This raises the question of its origin, possibly due to experience with cross-reacting antigens or of exposure to legionellas through their common occurrence in the environment. ${ }^{13}$ However, using the criteria that a fourfold or greater rise in antibody titre in suitably spaced paired sera or a titre $>256$ (confirmed with monovalent antigens) in a patient with clinical disease is suggestive of Legionella infection, there have been few difficulties in interpreting the results of the IFAT. High levels or rising titres of antibody to serogroups other than 1 have been recognised and in six subjects there was no antibody response to serogroup 1 , so that these cases could have been missed using monovalent serogroup 1 antigen alone.

Other workers have shown ${ }^{14}$ that there was a close correlation between the results of examination of human sera using a quadrivalent heat-killed antigen prepared from $L$ pneumophila serogroups $1-4$ and those obtained using monovalent serogroup 1 antigen. Eighteen sera, most containing antibody to $L$ pneumophila, when examined in parallel with that quadrivalent antigen and the presently-described quadrivalent antigen, gave results agreeing within one doubling dilution (HW Wilkinson, personal communication 1981). These workers also found that three of 20 sets of sera showed seroconversion detected by polyvalent antigen, but not serogroup 1 antigen. These were all seroconversions to serogroup 4 antigen and the titres obtained with monovalent serogroup 4 antigen agreed to within one doubling dilution with the titre obtained with polyvalent antigen. Hence, with heat-killed antigen there seems to be good reason for using a polyvalent antigen in order to detect monospecific antibody responses. In our experience, the appearance of the fluorescing organisms in the polyvalent antigen gives an immediate clue as to the specificity of the antibody response. Hence, antibody to serogroup 1 is recognised because this component of the antigen contains many filamentous and long bacillary forms, whereas serogroup 2 appears as occasional long and many very short forms. Serogroups 3 and 4 appear as short rods (as do serogroups 5 and 6 and other Legionella spp) in the IFAT.

Unlike FYSA, heat-killed antigens occasionally give a poorly staining, atypical appearance with some sera. These reactions are usually abolished by diluting serum in $E$ coli "blocking fluid"11 and hence would appear to be non-specific. Heat-killed antigen is easy to prepare and use and polyvalent antigens can be made quite simply.

At the present time, we are using four polyvalent antigen pools: (a) $L$ pneumophila serogroups 1-4; (b) L pneumophila serogroups 5 and 6; (c) L micdadei, $L$ bozemanii and $L$ dumoffii; (d) an experimental antigen comprising $L$ gormanii and two untyped $L$ pneumophila strains kindly provided by $\mathrm{Dr}$ JO'H Tobin. With these antigens antibody conversion to serogroup 5 and, in another patient, to one of $\mathrm{Dr}$ Tobin's strains have been recognised as have a high titre of antibody to serogroup 6 and $L$ micdadei respectively in a further two patients. However, validation of the performance of these antigens with human, as opposed to animal, antisera is difficult because sera containing antibody at a high titre to serogroups other than 1 are in very short supply.

We are grateful to Drs AD Macrae, Public Health Laboratory, Nottingham, AG Taylor, Division of Microbiological Research and Quality Control, Central Public Health Laboratory, Colindale, London, and JO'H Tobin of Oxford, for supplies of known positive sera; Drs RE Weaver and HW Wilkinson of the Centers for Disease Control, Atlanta, for strains of Legionella spp and confirmation of serological results respectively; to Mrs E Law for secretarial assistance, and to the Department of Audio-visual Services, Stobhill General Hospital, Glasgow, for the Figures.

\section{References}

${ }^{1}$ McKinney RM, Thomason BM, Harris PP, et al. Recognition of a new serogroup of the Legionnaires' disease bacterium. J Clin Microbiol 1979;9:103-7.

${ }^{2}$ McKinney RM, Thacker L, Harris PP, et al. Four serogroups of Legionnaires' disease bacterium defined by direct immunofluorescence. Ann Intern Med 1979;90: 621-4.

${ }^{3}$ Wilkinson HW, Fikes BJ, Cruce DD. Indirect immunofluorescence test for serodiagnosis of Legionnaires' disease. Evidence for serogroup diversity of Legionnaires' disease bacterial antigens and for multiple specificity of human antibodies. J Clin Microbiol 1979; 9:379-83.

${ }^{4}$ Fallon RJ, Abraham WH. Legionnaires' disease. Lancet $1978 ;$ ii: 1318.

${ }^{5}$ Feeley JC, Gibson RJ, Gorman GW, Longford NC, Rasheed JK, Mackel DC, Baine WB. Charcoal yeast extract agar primary isolation medium for Legionella pneumophila. J Clin Microbiol 1979;10:437-41.

${ }^{6}$ Horwitz MA, Silverstein SC. Legionnaires' disease bacterium (Legionella pneumophila) multiplies intracellularly in human monocytes. J Clin Invest 1980;66: 441-50.

${ }^{7}$ McDade JE, Shepard CC, Fraser DW, Tsai TR, Redus MA, Dowdle WA and the laboratory investigation team. Legionnaires' disease. Isolation of a bacterium and demonstration of its role in other respiratory disease. N Engl J Med 1977;297:1197-203. 
- Heimer GV, Taylor CED. Improved mountant for immunofluorescent preparations. J Clin Pathol 1974;27:254-6.

- Taylor AG, Harrison TG, Dighero MW, Bradstreet CMP. False positive reactions in the indirect fluorescent antibody test for Legionnaires' disease eliminated by use of formolised yolk-sac antigen. Ann Intern Med 1979;90:686-9.

${ }^{10}$ Fallon RJ. Laboratory diagnosis of Legionnaires' disease. ACP Broadsheet, 991981.

1 Wilkinson HW, Farshy CE, Fikes BJ, Cruce DD, Yealy LP. Measurement of immunoglobulin G-, M- and Aspecific titers against Legionella pneumophila and inhibition of titers against non-specific Gram-negative bacterial antigens in the indirect immunofluorescence test for legionellosis. J Clin Microbiol 1979;10:685-9.
${ }^{12}$ Fallon RJ, Abraham WH. Scottish Experience with the serologic diagnosis of Legionnaires' disease. Ann Intern Med 1979;90:684-6.

${ }^{13}$ Tobin JO'H, Swann RA, Bartlett CLR. Isolation of Legionella pneumophila from water systems: methods and preliminary results. $\mathrm{Br} \mathrm{Med} J 1981 ; 282$ :515-7.

${ }^{14}$ Wilkinson HW, Cruce DD, Broome CV. Validation of Legionella pneumophila indirect immunofluorescence assay with epidemic sera. J Clin Microbiol 1981;13: 139-46.

Requests for reprints to: Dr RJ Fallon, Department of Laboratory Medicine, Ruchill Hospital, Bilsland Drive, Glasgow G20 9NB, Scotland.

\section{Reports and Bulletins prepared by the Association of Clinical Biochemists}

The following reports and bulletins are published by the Association of Clinical Biochemists. They may be obtained from The Publishing Department, British Medical Journal (ACB Technical Bulletins), BMA House, Tavistock Square, London WC1H 9JR. Overseas readers should remit by British Postal or Money Order.

SCIENTIFIC REVIEWS (price $£ 1.00 / \$ 2.00$ each)

1 The assessment of thyroid function March 1971 FV FLYNN and JR HOBBS

2 Renal function tests suitable for clinical practice January 1972 FL MITCHELL, N VEALL, and RWE WATTS

3 Biochemical tests for the assessment of fetoplacental function May 1975 CE WILDE and RE OAKEY

4 Test of exocrine pancreatic function March 1977 AH GOWENLOCK

5 Assay of cholinesterase in clinical chemistry March 1979 ELSIE SILK, J KING, and MARY WHITTAKER

TECHNICAL BULLETINS (price $£ 1 \cdot 00 / \$ 2.00$ each)

22 Bilirubin standards and the determination of bilirubin by manual and technicon AutoAnalyzer methods January 1971 BARBARA BILLING, RUTH HASLAM, and N WALD

23 Interchangeable cells for spectrophotometers and fluorimeters September 1971 ss BROWN and AH GOWENLOCX

24 Simple tests to detect poisons March 1972 BW MEADE et al.

25 Blood gas analysers May 1972 K DIxoN

26 Kits for enzyme activity determination September 1972 SB ROSALKI and D TARLOW

27 Assessment of pumps suitable for incorporation into existing continuous flow analytical systems November 1972 A FLECK et al.

28 Routine clinical measurements of transferrin in human serum September 1973 K DIXON
29 Control materials for clinical biochemistry (5th edition) September 1973 JF STEVENS

30 Notes on the quality of performance of serum cholesterol assays September 1973 SS BROWN

31 Determination of uric acid in blood and in urine July 1974 RWE WATTS

32 A survey of amino acid analysers readily available in the United Kingdom September 1974 JE CARLYLE and P PURKISS

33 Definitions of some words and terms used in automated analysis November 1974 A FLECK, R ROBINSON, SS BROWN, and JR HOBBS

34 Measurement of albumin in the sera of patients January 1975 LINDA SLATER, PM CARTER, and JR HOBBS 35 Investigation of the validity of temperature correction factors for serum aspartate and alanine transaminases March 1975 SB ROSALKI et al.

36 Factors influencing the assay of creatinine November 1975 JGH COOK

37 A survey of enzyme reaction rate analysers readily available in the United Kingdom July 1977 RA SAUNDERS and RF BURNS

38 Transport of specimens for clinical chemistry analysis November 1977 P WILDING, JF ZILVA, and CE WILDE

39 A scheme for the evaluation of diagnostic kits May 1978 PH LLOYD

40 A practical guide to gamma-counting in radioimmunoassay January 1980 CE WILDE and D OTTEWELL

41 The use of biochemical tests in the diagnosis of disorders of calcium metabolism July 1980 ANGELA FAIRNEY 